\title{
Effect of Heat Treatment on the Bioactive Components and Antioxidant Activity in Selected Dry Beans and Nuts
}

\author{
Tunasamy Ketharin ${ }^{1 *}$, Lee Ley Shie ${ }^{1}$, Ponnaiah Paulraj ${ }^{1}$, Pazhayakath Thevarkattil \\ Mohamed Javad ${ }^{1}$, Pattammadath Sajeesh ${ }^{1}$, Keeyari Purayil Sajna ${ }^{1}$, Muruganandham \\ Chandramohan', Raji P. ${ }^{2}$ and Karanam Sai Bhavya²
}

${ }^{1}$ Department of Biomedical Sciences, Faculty of Medicine, MAHSA University, Bandar Saujana Putra, 42610 Jenjarom, Selangor Darul Ehsan, Malaysia. ${ }^{2}$ Department of Biotechnology, Sathyabama Institute of Science and Technology, JeppiaarNagar, Rajiv Gandhi Salai, Chennai - 600 119, India.

\begin{abstract}
Dry beans and nuts are vital in our daily diet and contains high dietary fiber, poly-unsaturated fatty acids and phytochemical compounds such as phenolic and flavonoids. The objective of this study was to compare the antioxidant activities in selected dry beans and nuts and the effect of roasting. Roasted and raw dried nuts and beans were grounded into powder, extracted in $70 \%$ methanol and evaporated. The methanol extracts were subjected to 1,1-Diphenyl-2-picrylhydrazyl (DPPH) scavenging assay, 2,2'-Azino-bis(3-ethylbenzothiazoline-6-sulfonic acid) (ABTS) assay, total phenolic content (TPC) assay and total flavonoid content (TFC) assay. Results were analyzed using ANOVA ( $p$ value $<0.05$ ). The results of DPPH, ABTS, TPC and TFC assays were found in increasing pattern from cashew nut (CN), almond (AN) to walnut (WN) among nuts, and from chickpea (CB), green pea (GB) to mung bean (MB) among beans. Whereas in roasted condition, increased activities were found in CN, $G B$ and $C B$ while decreased activities were found in AN, WN and MB for DPPH assay. In ABTS assay, increased activities were found in $\mathrm{CN}, \mathrm{GB}, \mathrm{CB}$ and $\mathrm{MB}$ but decreased activities were found in AN and WN. For TPC assay, increased activities were found in all of beans and nuts except for WN. As for TFC assay, decreased activities were found among all nuts and beans except for $\mathrm{CN}$ and $\mathrm{CB}$. The study indicates roasting process alters the antioxidant capacity (DPPH and ABTS), TPC and TFC in dry beans and nuts.
\end{abstract}

Keywords: Antioxidant; nuts; beans.

*Correspondence: ketharin@mahsa.edu.my

(Received: 15 March 2019; accepted: 26 April 2019)

Citation: Tunasamy Ketharin, Lee Ley Shie, Ponnaiah Paulraj, Pazhayakath Thevarkattil Mohamed Javad, Pattammadath Sajeesh, Keeyari Purayil Sajna, Muruganandham Chandramohan, Raji P., and Karanam Sai Bhavya, Effect of Heat Treatment on the Bioactive Components and Antioxidant Activity in Selected Dry Beans and Nuts, J Pure Appl Microbiol., 2019; 13(2): 915-922. doi: 10.22207/JPAM.13.2.28

C The Author(s) 2019. Open Access. This article is distributed under the terms of the Creative Commons Attribution 4.0 International License which permits unrestricted use, sharing, distribution, and reproduction in any medium, provided you give appropriate credit to the original author(s) and the source, provide a link to the Creative Commons license, and indicate if changes were made. 


\section{INTRODUCTION}

Nuts are highly nutritious and rich in carbohydrates, proteins, mono- and polyunsaturated fatty acids, vitamin E, minerals, fat- soluble bioactive compounds, phenolic acids, and flavonoids (Alasalvar et al., 2015). In this new global era, most of the people have shifted gradually away from healthy diet due to rapid growth in agriculture, industry, economy and changes in social behavior (Popkin et al., 2012; Zhai et al., 2014). Intake of grain involves cereals and legumes, fruits, vegetables, nuts, and beans which has become increasingly rare due to hectic human lifestyle. Consumption of food high in fat and salt have been adopted (Hu et al., 2012) which could result in increased risk of disease development, including diabetes mellitus, cardiovascular diseases, hypertension, and development of cancers such as colon cancer or gastric cancer. Therefore, the assessment of daily nutrient intake in human has become essential to maintain a balanced nutritional status (Zhang et al., 2015).

Free radical molecules are highly reactive substances tend to accept electrons from other biological molecules. The oxidants include reactive oxygen species (ROS), reactive nitrogen species (RNS) and non-free radical species. They are highly reactive molecules with at least one unpaired electron (Gulcin,2012). The generation of free radical molecules result in induction of oxidative damage to the biological molecules such as carbohydrates, proteins, lipids, and nucleic acids. The degradation of these biological molecules lead to ageing, chronic disease and cancer. Several studies have suggested that ROS are associated with some diseases, including diabetes, coronary heart disease, arterio-sclerosis, breast cancer and colorectal cancer (Tanizawa et al., 1992; Duh, 1998).

Antioxidants have the ability to terminate the oxidation. The most common antioxidants are ascorbic acid, tocopherol, flavonoid and phenolic acid. They could transfer single electron to the free radical while itself remains in a reducing state (Gulcin, 2012).

The natural antioxidants in the nuts have been widely studied to determine their biological properties. Traditionally, nuts provided positive effect on immunity, digestion, wound healing, analgesic as well as circulation (Casas-Agustench et al.,2011). Several recent observations have suggested that daily intake of 28 to $100 \mathrm{~g}$ could reduce the risk of cardio-vascular disease. This contributes to phytochemical antioxidants and low saturated fatty acids and high mono- and poly-unsaturated fatty acids. The LDL-cholesterol levels are significantly decreased by replacing saturated fatty acids with unsaturated fatty acids. The phytochemical antioxidants in the nuts may relatively inhibit low density lipoprotein (LDL) oxidation. Combination of these two mechanisms protect LDL from adhering on the inner wall of blood vessels and thus reduces the risk of cardiovascular disease (Abe et al., 2010).

The activity of the antioxidant is suspected to dramatically decrease after roasting, due to thermal degradation of nutrient and phenolic antioxidants. The roasting process could provide a significant effect on the bioactive compound and antioxidant activity in the beans and nuts. This study would be able to provide useful information to the consumers and incentives to food manufacturers.

The objective of this study is to determine the effect of heat treatment on the bioactive components and antioxidant activity in selected nuts and dry beans through analysis of 2,2-Diphenyl-1-picrylhydrazyl radical (DPPH) scavenging assay, 2,2-Azinobis 3-ethylbenzthiazoline-6-sulphonic acid radical (ABTS) scavenging assay, total phenolic content (TPC) assay and total flavonoids content (TFC) assay.

\section{MATERIALS AND METHODOLOGY Sample preparation}

The dry and roasted dry beans and nuts samples were prepared as described by Boateng et al.(2008) with slight modification. $50 \mathrm{~g}$ of cashew nut (CN), almond (AN), walnut (WN), chickpea (CB), green pea (GB) and mung bean (MB) were grounded into powder form respectively. Another $50 \mathrm{~g}$ of each samples were roasted in the microwave oven with $900 \mathrm{~W}$ for 6 minutes. The roasted samples were then cooled and grounded into powder form. The powdered samples were sealed in plastic bags and stored at temperature of $-4^{\circ} \mathrm{C}$.

\section{Extraction}

The roasted and dry beans and nuts extracts were prepared as described by Boateng 
et al. (2008) with slight modification. Methanol/ water solvent in ratio of 7:3 were prepared. $25 \mathrm{~g}$ of each sample were added into $250 \mathrm{~mL}$ of solvent. The mixture were then placed on the vibration shaker for 16 hours at room temperature. Then, the samples were centrifuged at $3000 \mathrm{~g}$ for 20 minutes. The supernatant was obtained and evaporated at temperature of $40^{\circ} \mathrm{C}$ by rotatory evaporator. The extract was stored at $-4^{\circ} \mathrm{C}$.

\section{DPPH assay}

The DPPH assay was measured as described by Boateng et al. (2008)with slight modification. $20 \mu \mathrm{L}$ of sample or standard was added with $180 \mu \mathrm{L}$ of $\mathrm{DPPH}$ solution at concentration of $200 \mathrm{mmol} / \mathrm{L}$ and incubated for 30 minutes in dark at room temperature. After incubation, the absorbance was measured at 520 $\mathrm{nm}$. Ascorbic acid was used as standard. DPPH scavenging activity were calculated as in (1).

$$
\begin{aligned}
& \begin{array}{c}
\text { DPPH radical } \\
\text { scavenging } \\
\text { activity (\%) }
\end{array}=\frac{\begin{array}{c}
\text { Absorbance }- \text { Absorbance } \\
\text { Control Sample }
\end{array}}{\text { Absorbance Control }}-100 \%
\end{aligned}
$$

\section{ABTS assay}

ABTS assay was measured as described by Re et al. (1999) and Boateng et al. (2008). 6.62mg of potassium persulfate $(2.45 \mathrm{mM})$ and $38.4 \mathrm{mg}$ of ABTS $(7 \mathrm{mM})$ were measured and dissolved in $10 \mathrm{~mL}$ of deionized water. The mixture was stored in dark for 16 hours at room temperature for preparation of cation ABTS+. ABTS+ was diluted until an absorbance of $0.7 \mathrm{~A}$ was observed. $20 \mu \mathrm{L}$ of sample or standard was added with $200 \mu \mathrm{L}$ of diluted ABTS. The absorbance was measured at $730 \mathrm{~nm}$ after exactly 1 minute. The unit of concentration of ABTS+ was expressed as $\%$ and calculated as in (2). Trolox was used as standard.

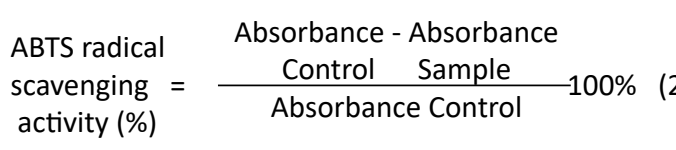

\section{TPC assay}

The TPC assay was measured using the method as described by Oki et al.( 2012). with slight modification. Folin-Ciocalteau reagent was diluted into 1:10 with distilled water. $50 \mu \mathrm{L}$ of Folin-Ciocalteau reagent was added with $10 \mu \mathrm{L}$ of sample or standard. This mixture was incubated for 5 minutes at room temperature in the dark.
$100 \mu \mathrm{L}$ of $70 \mathrm{~g} / \mathrm{L}$ sodium carbonate was added and incubated for 1.5 hours at room temperature in the dark. The absorbance of the samples was measured at $405 \mathrm{~nm}$. The TPC was calculated as in (3) and expressed in $\mathrm{mg}$ (gallic acid equivalent)/g. (GAE, is the Gallic Acid Equivalence $(\mathrm{mg} / \mathrm{ml}), \mathrm{V}$, is the volume of extract $(\mathrm{ml}), M=$ the weight of pure plant extract (g).

$$
\mathrm{TPC}=\frac{(\mathrm{GAExV})}{\mathrm{M}}
$$

\section{TFC assay}

The TFC assay was measured as described by Chang et al. (2002) with slight modification. $112 \mu \mathrm{L}$ of distilled water was added with $4 \mu \mathrm{L}$ of $100 \mathrm{~g} / \mathrm{L}$ aluminium chloride, $20 \mu \mathrm{L}$ of sample, $60 \mu \mathrm{L}$ methanol and $4 \mu \mathrm{L}$ of $50 \mathrm{~g} / \mathrm{L}$ potassium acetate. The mixture was then incubated for 30 minutes at room temperature in the dark. The absorbance of the sample was measured at $510 \mathrm{~nm}$ against the catechin standard $(0.001 \mathrm{mg} / \mathrm{mL})$. The TFC was calculated as in (4) and expressed as $\mathrm{mg}$ (catechin equivalent)/g.(QE, is Quercetin Equivalence ( $\mu \mathrm{g} /$ $\mathrm{ml}), \mathrm{V}$, is the volume of extract $(\mathrm{ml}), \mathrm{m}$, the weight of pure plant extract $(\mathrm{g})$.

$$
\mathrm{TFC}=\frac{\mathrm{QExV}}{\mathrm{m}}
$$

\section{Statistical analysis}

All test was run as triplicates and data would be expressed as mean \pm standard deviation (Mean $\pm S D$ ). Statistical significance of mean values among the samples were determined by ONE WAY ANOVA using SPSS statistic software. P value of less than 0.05 was considered statistically significant.

\section{RESULTS}

DPPH

As in figure 1, the DPPH scavenging effect were lowest in raw CB (16.869 $\pm 5.124 \%)$, followed by raw CN (42.636 $\pm 8.090 \%)$, raw GB $(65.380 \pm 3.242 \%)$, raw AN (83.032 $\pm 0.481 \%)$, raw MB (86.272 $\pm 2.728 \%)$, and raw WN (91.346 $\pm 1.067 \%)$. Whereas, in roasted samples, the DPPH scavenging effect were lowest in roasted CB $(52.160 \pm 4.366 \%)$, followed by roasted GB $(69.907 \pm 1.682 \%)$, roasted AN (70.868 \pm 1.734 $\%)$, roasted WN (77.634 $\pm 2.415 \%)$, roasted CN $(78.725 \pm 1.640 \%)$, and roasted MB (84.007 \pm $1.596 \%)$. Raw $C N$ has a significantly $(P<0.001)$ 
DPPH scavenging effect (\%) against different types of nuts and dry beans

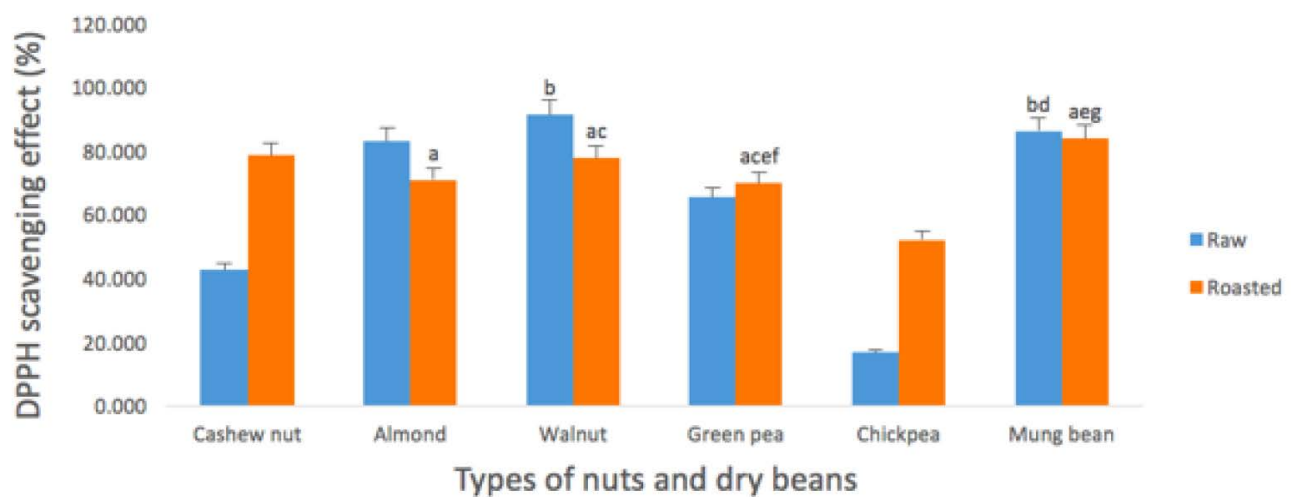

a indicates NS (non-significant) when compared with roasted cashew nut

$\mathrm{b}$ indicates NS when compared with raw almond $\mathrm{c}$ indicates NS when compared with roasted almond

$d$ indicates NS when compared with raw walnut

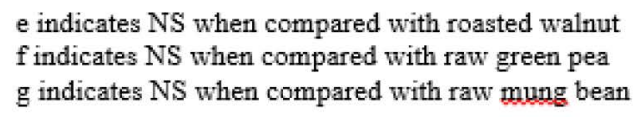

Fig. 1. DPPH scavenging effect (\%) in raw and roasted dry beans and nuts

lower DPPH scavenging effect compared to both raw $A N$ and raw WN. There was no significant difference between raw WN and raw AN. DPPH value is significantly lower in raw $C B$ compared to raw $\mathrm{MB}$ and raw $\mathrm{GB}$. Raw $\mathrm{MB}$ has a significantly higher DPPH value compared to raw $C B$ and raw $\mathrm{GB}$. There is no significant difference between raw $\mathrm{WN}$ and raw $\mathrm{MB}$. After roasting, roasted $\mathrm{CN}$ and roasted $C B$ have significantly increased antioxidant capacity compared to raw $\mathrm{CN}$ and raw $\mathrm{CB}$, whereas roasted $A N$ and roasted $W N$ have significantly decreased antioxidant activity compared to raw AN and raw WN. There is no significant difference in $\mathrm{GB}$ and $\mathrm{MB}$ before and after roasting. Roasted $\mathrm{CB}$ has the significantly lowest DPPH scavenging effect among the roasted dry beans and nuts. There is no significant difference among roasted $\mathrm{WN}$, roasted $\mathrm{MB}$ and roasted $\mathrm{CN}$.

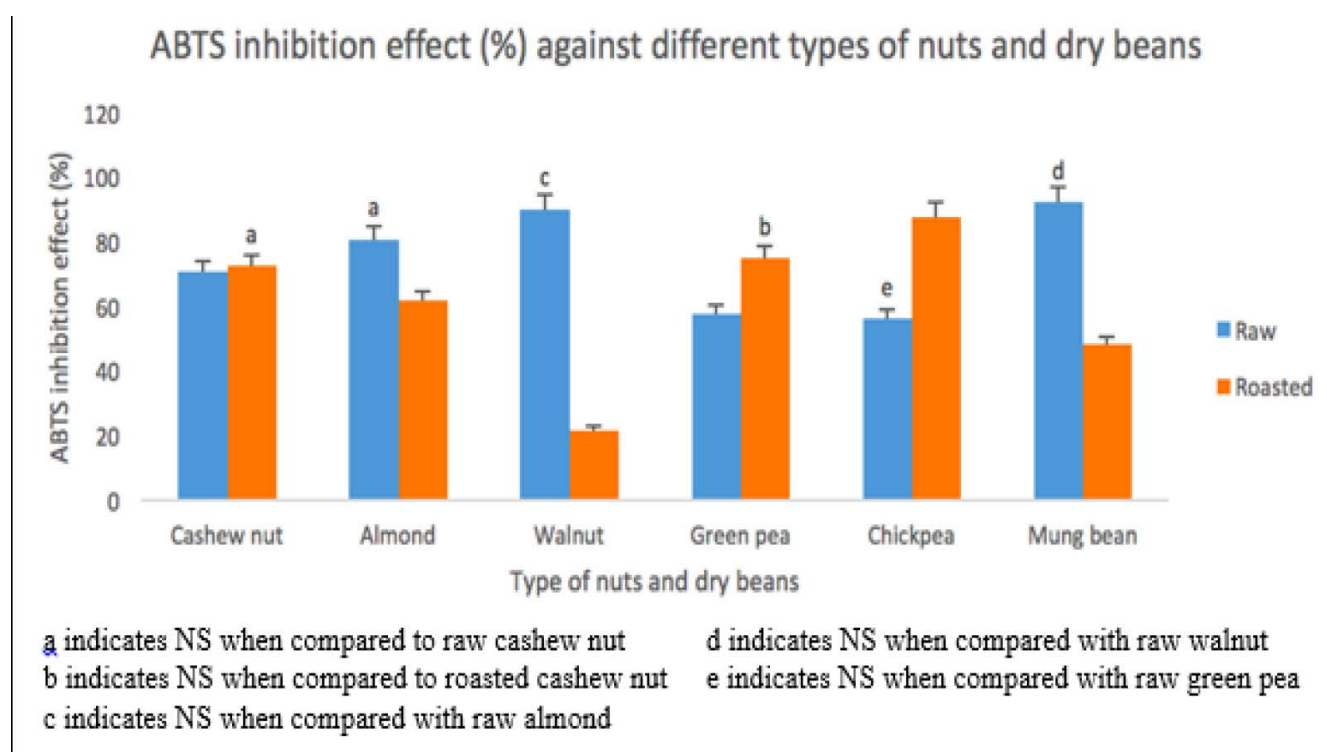

Fig. 2. ABTS inhibition effect (\%) in raw and roasted dry beans and nuts 


\section{ABTS}

The ABTS inhibition effect in Fig. 2 were lowest in raw $\mathrm{CB}(56.272 \pm 2.246 \%)$, followed by raw GB $(57.815 \pm 1.325 \%)$, raw $\mathrm{CN}(70.703$ $\pm 1.137 \%)$, raw $\mathrm{AN}(80.754 \pm 5.953 \%)$, raw $\mathrm{WN}$ $(90.307 \pm 0.238 \%)$, raw MB $(92.314 \pm 1.965 \%)$. As for roasted samples, lowest ABTS inhibition effect were in roasted WN (21.801 $\pm 1.260 \%)$, followed by roasted $\mathrm{MB}(48.470 \pm 4.120 \%)$, roasted $\mathrm{AN}$ $(61.739 \pm 8.254 \%)$, roasted CN (72.609 \pm 2.057 $\%)$, roasted GB (75.059 $\pm 2.880 \%)$ and roasted $\mathrm{CB}(87.946 \pm 2.695 \%)$. ABTS value in raw $\mathrm{WN}$ was significantly higher $(P<0.001)$ compared raw $C N$. There is no significant difference between raw $W N$, raw $A N$ and raw $M B$. There is also no significant difference between raw $G B$ and raw $C B$. After roasting, $G B$ and $C B$ have significantly increased antioxidant activity compared to raw $G B$ and CB. Roasted AN, WN and MB have significantly decreased antioxidant activity compared to raw $\mathrm{AN}, \mathrm{WN}$ and $\mathrm{MB}$. There is no significant difference in CN. Roasted walnut has the significantly lowest ABTS inhibition effect compared to other roasted dry beans and nuts. There is no significant difference between roasted $\mathrm{CN}$ and roasted $\mathrm{GB}$. Roasted CB has the significantly highest $A B T S$ value compared to other dry beans and nuts.

TPC

The TPC as in figure 3 indicates lowest level in raw $\mathrm{CN}(6.637 \pm 0.238 \mathrm{mg} / \mathrm{g})$, followed by raw $\mathrm{CB}(7.084 \pm 0.374 \mathrm{mg} / \mathrm{g})$, raw $\mathrm{AN}(7.176 \pm$ $0.364 \mathrm{mg} / \mathrm{g})$, raw WN $(8.097 \pm 0.126 \mathrm{mg} / \mathrm{g})$, raw GB $(9.503 \pm 0.260 \mathrm{mg} / \mathrm{g})$ and raw MB (14.346 \pm 0.542 $\mathrm{mg} / \mathrm{g})$. As for the roasted samples, TPC value was lowest in roasted WN (3.943 \pm 0.043$)$, followed by roasted AN (8.366 \pm 0.606$)$, roasted GB (9.961 $\pm 0.162)$, roasted $\mathrm{CN}(11.324 \pm 0.554)$, roasted $\mathrm{CB}(13.468 \pm 0.177)$ and roasted MB (13.921 \pm 0.538). Raw $W N$ has significantly $(P<0.01)$ higher TPC compared to raw $\mathrm{CN}$. There is no significant difference between raw $\mathrm{CN}$, raw $\mathrm{AN}$ and raw $\mathrm{WN}$. Raw $M B$ was significantly higher than raw GB and raw $C B$. Raw $C B$ has the significantly lowest TPC among the dry beans. TPC value in roasted $C N$, roasted $A N$ and roasted $C B$ has significantly increased after roasting whereas roasted WN has decreased. There is no significant difference found in $\mathrm{GB}$ and $\mathrm{MB}$ after roasting. Roasted $\mathrm{WN}$ has the significantly lowest and roasted MB has the highest TPC value among the roasted dry beans and roasted nuts.

TFC

As in figure 4, the TFC level is lowest in raw $\mathrm{CN}(0.519 \pm 0.088 \mathrm{mg} / \mathrm{g})$, followed by raw $\mathrm{CB}$ $(0.837 \pm 0.098 \mathrm{mg} / \mathrm{g})$, raw AN $(1.712 \pm 0.210 \mathrm{mg} / \mathrm{g})$, raw GB (2.294 $\pm 0.281 \mathrm{mg} / \mathrm{g})$, raw WN (2.494 \pm $0.609 \mathrm{mg} / \mathrm{g})$ and raw $\mathrm{MB}(5.611 \pm 0.684 \mathrm{mg} / \mathrm{g})$. After roasting, the TFC level was lowest in roasted AN (1.368 \pm 0.290$)$, followed by roasted GB (1.400 $\pm 0.158)$, roasted $W N(1.433 \pm 0.207)$, roasted CN

\section{Total phenolic content of nuts and dry beans}

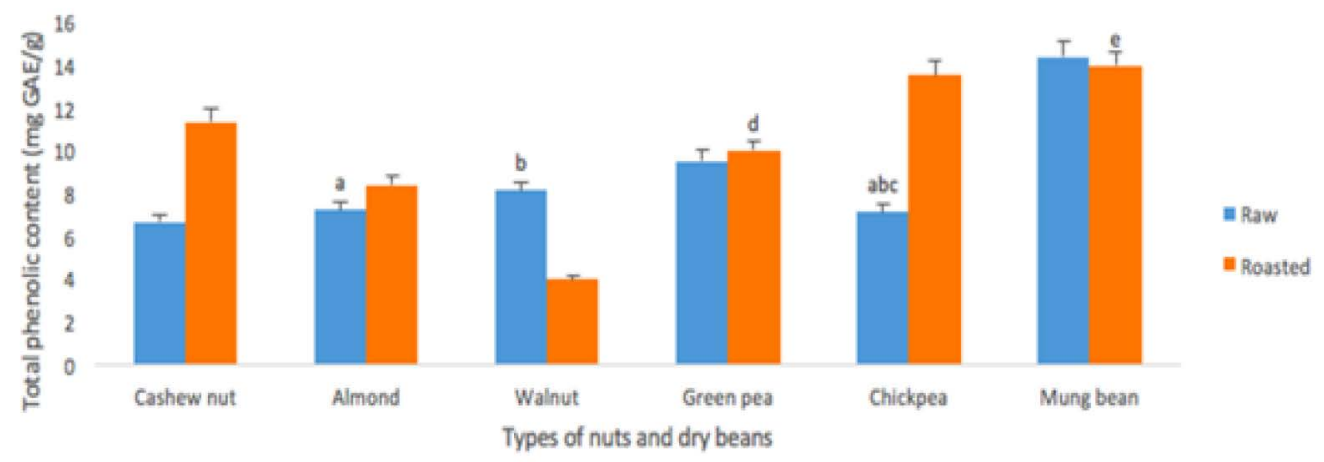

a indicates NS when compared with raw cashew nut $\mathrm{b}$ indicates NS when compared with raw almond $c$ indicates NS when compared with raw walnut d indicates NS when compared with raw green pea e indicates NS when compared with raw mung bean

Fig. 3. TPC in raw and roasted dry beans and nuts 


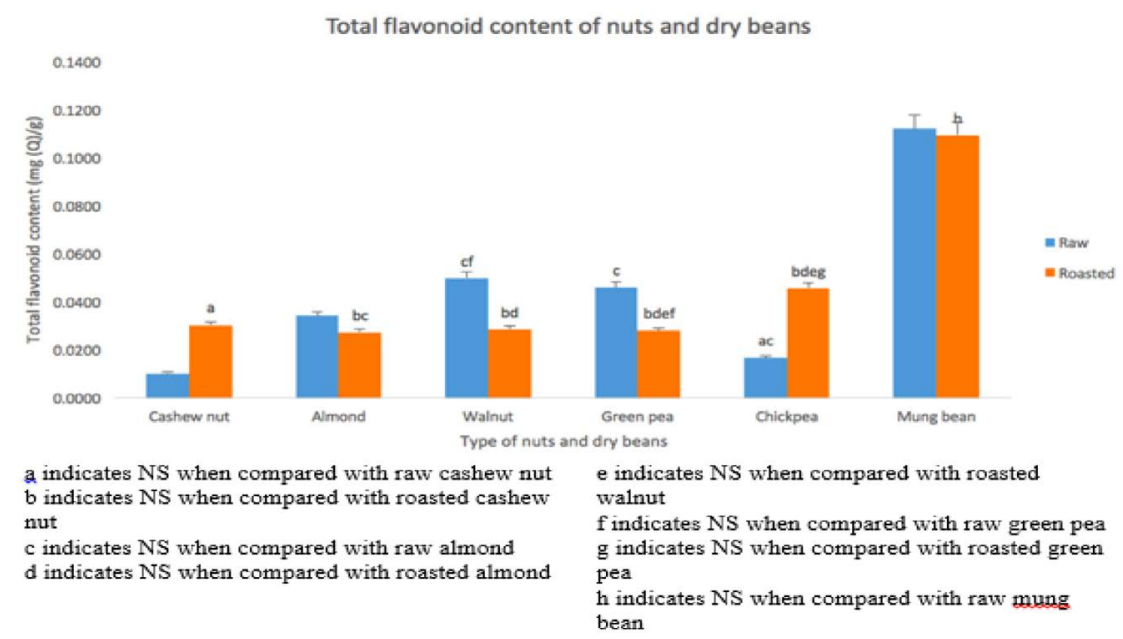

Fig. 4. TFC in raw and roasted dry beans and nuts

$(1.520 \pm 0.302)$, roasted CB $(2.290 \pm 0.379)$ and roasted $\mathrm{MB}(5.479 \pm 0.409)$. TFC in raw $\mathrm{WN}$ was significantly $(P<0.001)$ higher than raw $C N$. No significant difference found between raw AN and raw WN. Raw CN has the significantly lowest TFC value among the nuts. Raw MB has significantly higher TFC value compared to raw $\mathrm{GB}$ and raw $\mathrm{CB}$. Raw CB has significantly lowest TFC value among the dry beans. TFC in raw MB was significantly higher compared to raw WN. TFC in roasted CB has significantly increased after roasting whereas roasted WN has significantly decreased. The other roasted dry beans and nuts show no significant difference. Roasted MB has significantly higher TFC among roasted dry beans and nuts.

\section{DISCUSSION}

The DPPH, ABTS, TPC and TFC values in raw samples were found in pattern of increasing from $\mathrm{CN}<\mathrm{AN}<\mathrm{WN}$ among nuts and $\mathrm{CB}<\mathrm{GB}<\mathrm{MB}$ among beans. Upon roasting, there were variation in antioxidant and bioactive compound values.

There was an increase in DPPH and ABTS scavenging activities among $C N, G B$ and $\mathrm{CB}$ and a decrease among $\mathrm{AN}, \mathrm{WN}$ and $\mathrm{MB}$. These variation could be due to the different mechanism of reaction. According to a study by Gulcin (2012), antioxidant activity could be divided according to the reaction mechanism into; hydrogen atom transfer (HAT) and single electron transfer (SET). HAT-based methods assess the ability of antioxidant to donate the proton for scavenging the free radical whereas SET-based methods measure the ability of antioxidant to transfer a single electron for quenching the free radical. Different types of nuts and beans may have a different mechanism of reaction upon heat treatment or a combination of both mechanism which could react antagonistically or synergis-tically and thus could lead to variation in scavenging activity level. The antioxidant levels pattern in both DPPH and ABTS scavenging activities varies in general. This difference may be due to difference in incubation time, mechanism of action in test reaction and type of antioxidant measured. Gulcin (2012) has proposed that results produced by ABTS are related kinetic behavior of antioxidant standard compounds.

In a study by Anar et al. (2009), the total antioxidant capacity values of nuts were lower in cashew nut, followed by almond with skin and walnut, which was similar with present study results. The study suggested that the high total antioxidant capacity (TAC) in walnut is mostly attributed to the high polyphenol content. Most of the phenolic compounds commonly found in the skin of walnut includes phenolic acids and condensed tannins, which have been identified to have a very high antioxidant activity. In cashew nut, anacardic acids, cardanols, and cardols have been identified as preventive antioxidants. They only cease the activity of pro-oxidant enzyme such as NADPH dependent oxidase to prevent formation of ROS, but do not scavenge ROS (Kubo et al.,2006).

The decreased level of antioxidant observed in roasted samples ( $A N, W N$ and $M B$ ) 
could be suggested due to degradation of large amount of heat labile antioxidants. Roasting is a heat treatments that could have destroyed the heat sensitive antioxidants and thus results in decreased TAC. Acar and his colleagues has proposed that roasting process may have influence on antioxidant capacity (Anar et al.,2009). In his study, they described that short roasting time causes decrease in TAC in most of samples. When the roasting time was prolonged, TAC value in the dry beans and nuts tend to increase.

Whereas, CN, GB and CB had significantly increased antioxidant capacity after roasting. This can be due to Maillard reaction which leads to formation of new compounds with antioxidant properties. High-starch content materials may result in greatly increased antioxidant activity. Maillard reaction involves complex series of chemical reaction between amino acids and reducing sugar. It is a non-enzymatic reaction and favors low water environment and high temperature. Melanoidins is an example of maillard reaction product which contain many phenol groups and has antioxidant properties (Pastoriza \& Rufian-Henares, 2014).

The amount of phenols and flavonoids recorded in roasted samples varies in this study. TPC values of roasted samples were increased in $C N, A N, G B$ and $C B$ but decreased in $W N$ and $M B$. Whereas in TFC, the values were increased in $A N, W N, G B$ and $M B$ but decreased in $C N$ and $\mathrm{CB}$. Reynoso-Camacho and his colleague has proposed that the seed color of beans determines the presence and concentration of polyphenolic compound (Reynoso-Camacho et al.,2006). Madhujith et al. (2004) had identified that there is high amount of polyphenolic compound found in dry beans with red, brown and black color coats whereas white dry beans contain small amount of polyphenolic compound, especially flavonoid. Aparicio-Fernandez and his colleague have explained that proanthocyanidins are the flavonoid that is widely distributed in dry beans, which has a greater antioxidant activity than simple phenolic. Phenolic compounds including flavonoids and phenolic acids in the dry beans and nuts are present in either soluble form or forms complex with cell wall (Aparicio-Fernandez et al.,2005).
A study by Ahmed and Ali(2013), suggested that high surface area of samples in powder form when cooked results in more disruption of cell and breakdown of phenolic compounds at high temperature similarly with prolonged cooking. In addition, loss of phenolic compound could also be due to breakdown of phenolic during drying process. Most of the phenolic compounds are unstable at high temperature and soluble in water. Dewanto et al.(2002) had explained that thermal process could destroy the cell wall or breakdown the insoluble phenolic compounds and results in release of bound phenolic acids during extraction time.

The variation in difference of antioxidant compared to phenolic and flavonoid level among the beans and nuts could be as result of presence of potential antioxidants other than phenolic and flavonoid. It could be also suggested, for high-starch content material such as $\mathrm{CN}$ and $\mathrm{CB}$, their increased antioxidant activity could be accompanied by progressive increased formation of new complex mixtures of different types of antioxidants. Presence of phytochemicals other than phenolics such as tocopherol or pigments may play prominent role in antioxidant capacity of dry nuts and beans with lower TPC and TFC levels.

\section{CONCLUSION}

Among the dry beans and nuts, raw $\mathrm{MB}$ and raw WN have the highest bioactive compound with antioxidant activity. The roasting process might have both positive and negative influence on bioactive component and antioxidant activity level. The balance between thermal degradation of natural antioxidant and formation of new compound having antioxidant activity is greatly affected by roasting process. After roasting process, $\mathrm{CN}, \mathrm{GB}$ and $\mathrm{CB}$ increases their antioxidant activity whereas $\mathrm{AN}, \mathrm{WN}$ and $\mathrm{MB}$ activities were decreased. However, the order in each assay is different. The study indicates roasting process alters the bioactive components level (TPC and TFC) and antioxidant capacity (DPPH and ABTS) in dry beans and nuts. The present studies have showed that nuts and dry beans have high antioxidant activity and could be considered as an excellent sources of natural antioxidants and should be considered as an integral part of human daily diet. 


\section{ACKNOWLEDGEMENTS}

The authors wish to acknowledge the financial support of Department of Biomedical Science, MAHSA University and thank Dr. V. Appalaraju, HOD, Lecturer, Department of Medical Chemistry, MAHSA University for their aid and knowledge in completing the study.

\section{CONFLICT OF INTEREST}

The authors declare that there is no conflict of interest.

\section{AUTHORS' CONTRIBUTION}

All authors have made substantial, direct and intellectual contribution to the work and approved it for publication.

\section{FUNDING}

None

\section{DATA AVAILABILITY}

All datasets generated or analyzed during this study are included in the manuscript.

\section{ETHICS STATEMENT}

This article does not contain any studies with human participants or animals performed by any of the authors.

\section{REFERENCES}

1. Alasalvar C., Bolling B.W. Review of nut phytochemicals, fat-soluble bio-actives, anti-oxidant components and health effects. British Journal of Nutrition, 2015; 113(2): 568-578.

2. Popkin B.M., Adair L.S., Ng S.W. NOW AND THEN: Global nutrition transition and the pandemic of obesity in developing countries. Nutrition Reviews, 2012; 70(1): 3-21.

3. Zhai F., Du S., Wang Z., Zhang J., Du W., Popkin B. Dynamics of the chinese diet and the role of urbanicity, 1991-2011. Obesity Reviews, 2014; 15(1): 16-26.

4. Hu S., Kong L., Gao R., Zhu M., Wang W., Wang Y., Wu Z., Chen W., Liu M. Outline of the report on cardiovascular disease in china, 2010. Biomedical and Environmental Sciences, 2012; 25(3): 251-256.

5. Zhang R.H., Wang Z.P., Fei Y., Zhou B., Zheng S.S., Wang L.J., Huang L.C., Jiang S.Y., Liu Z.Y., Jiang J.X., Yu Y.X. The Difference in Nutrient Intakes between Chinese and Mediterranean, Japanese and American Diets. Nutrients, 2015; 7(6): 4661-4688.

6. Gulcin I. Antioxidant activity of food constituents: An overview. Archives of Toxicology, 2012; 86: 345-391.

7. Tanizawa H., Ohkawa Y., Takino Y., Ueno A., Kageyama T., Hara S. Studies on natural anti-oxidants in citrus species. I. Determination of antioxidant activities of citrus fruits. Chemical and Pharmaceutical Bulletin, 1992; 40: 1940-1942.

8. Duh P.D. Antioxidant activity of burdock (ArctiumlappaLinne): its scavenging effect on free radical and active oxygen. Journal of the American Oil Chemist's Society, 1998; 75: 455-465

9. Casas-Agustench P., Salas-Huetos A., Salas-Salvado J. Mediterranean nuts: origins, ancient medicinal benefits and symbolism. Public Health Nutrition, 2011; 14: 2296-2301.

10. Abe L.T., Lajolo F.M., Genovese M.I. Comparison of phenol content and antioxidant capacity of nuts. Ci7 ncia e Tecnologia de Alimentos, 2010; 30(1): 254-259.

11. Boateng J., Verghese M., Walker L.T., Ogutu S. Effect of processing on antioxidant contents in selected dry beans (Phaseolus spp. L.). Food Science and Technology, 2008; 41(9): 1541-1547.

12. Re R., Pellegrini N., Proteggente A., Pannala A., Yang M., Rice-Evans C. Antioxidant Activity Applying An Improved ABTS Radical Cation-Decolorization Assay. Free Radical Biology \& Medicine, 1999; 26(9-10): 1231-1237.

13. Oki T., Masuda M., Furuta S., Nishiba Y., Terahara N., Suda I. Involvement of Anthocyanins and other Phenolic Compounds in Radical-Scavenging Activity of Purple-Fleshed Sweet Potato Cultivars. Journal of Food Science, 2002; 67(5): 1752-1756.

14. Chang C.C., Yang M.H., Wen H.W., Chern J.C. Estimation of Total Flavonoid Content in Propolis by Two Complementary Colorimetric Methods. Journal of Food and Drug Analysis, 2002; 10(3): 178-182.

15. Acar O.C., Vural Gokmen V., Pellegrini N., Fogliano V. Direct evaluation of the total antioxidant capacity of raw and roasted pulses, nuts and seeds. European Food Research and Technology, 2009; 229: 961-969.

16. Kubo I., Masuoka N., Ha T.J., Tsujimoto K. Antioxidant activity of anacardic acids. Food Chemistry, 2006; 99(3): 555-562.

17. Pastoriza S., and Rufian-Henares J.A. Contribution of melanoidins to the antioxidant capacity of the Spanish diet. Food chemistry, 2014; 164: 438-445.

18. Reynoso-Camacho R., Ramos-Gomez M., LoarcaPina G. Bioactive components in common beans (Phaseolus vulgaris L.). Advances in Agricultural and Food Biotechnology, 2006: 217-236.

19. Madhujith T., Amarowicz R., Shahidi F. Phenolic antioxidants in beans and their eVects on inhibition of radical-induced DNA damage. Journal of American Oil Chemist's Society, 2004; 81(7): 691-696.

20. Aparicio-Fernandez X., Yousef G.G., Loarca-Pina G., de Mejia E., Lila M.A. Characterization of polyphenolics in the seed coat of Black Jamapa bean (Phaseolus vulgaris L.). Journal of Agricultural and Food Chemistry, 2005; 53(11): 4615-4622.

21. Ahmed F.A., and Ali R.F.M. Bioactive Compounds and Antioxidant Activity of Fresh and Processed White Cauliflower. BioMed Research International, 2013: 367819.

22. Dewanto V., Wu X., Liu R.H. Processed sweet corn has higher antioxidant activity. Journal of Agricultural and Food Chemistry, 2002; 50(17): 4959-4964. 